\title{
Penyesuaian diri mahasiswa yang kuliah sambil bekerja
}

\author{
Reyvences Asgrenil Lusi ${ }^{(1)}$
}

\begin{abstract}
${ }^{(1)}$ Fakultas Psikologi, Universitas Surabaya, Surabaya, Indonesia
Oftentimes, some students should work while studying, which poses certain challenges for them to undergo such a dual role. This study aimed to investigate the forms of selfadjustment experienced by master students who work while studying. Designed as qualitative research, we used an interview to collect data, which were analyzed by grouping the informant's responses into several themes or topics. The participant or informant in this research is a master student who is working while studying. The results indicated that the informant has made some self-adjustments in his life, be they emotional or cognitive. Despite this attainment, there are still some aspects of self-adjustment that have not been carried out by the informant. These results overall imply that self-adjustment is a psychological dynamic that accompanies students who should work while studying.
\end{abstract}

Keywords: master student, self-adjustment, working while studying

Kuliah sambil bekerja merupakan fenomena yang sering terjadi, yang memberikan tantangan tertentu bagi mahasiswa yang menjalani peran ganda tersebut. Penelitian ini bertujuan untuk mengetahui bentuk penyesuaian diri yang dilakukan oleh mahasiswa yang kuliah sambil bekerja. Penelitian ini menggunakan pendekatan penelitian kualitafif. Analisis data dilakukan dengan mengelompokkan respon informan ke dalam beberapa tema atau topik. Informan dalam penelitian ini adalah seorang mahasiswa yang sedang menjalani studi di program magister yang sekaligus seorang karyawan. Hasil penelitian menunjukkan bahwa informan telah melakukan penyesuaian diri dalam kehidupannya baik sebagai mahasiswa dan juga sebagai karyawan. Bentuk penyesuaian diri yang dilakukan oleh informan yaitu penyesuaian diri secara emosional dan penyesuaian diri secara kognitif. Terlepas dari capaian tersebut, masih terdapat beberapa aspek dalam penyesuaian diri yang belum secara efektif dilakukan oleh informan. Hasil penelitian ini mengimplikasikan bahwa penyesuaian diri merupakan dinamika psikologis yang mengiringi mahasiswa yang kuliah sambil bekerja.

Kata kunci: kuliah sambil bekerja, mahasiswa program magister, penyesuaian diri

MEDIAPSI, 2021, Vol. 7(1), 5-16, DOI: https://doi.org/10.21776/ub.mps.2021.007.01.2

Received: 04-02-2020. Revised: 02-10-2020. Accepted: 07-11-2020. Published online: 24-06-2021

Handling Editor: Sumi Lestari, Universitas Brawijaya, Malang, Indonesia

*Corresponding author: Reyvences Asgrenil Lusi, Fakultas Psikologi, Universitas Surabaya, Surabaya,

Indonesia. E-mail: lusireyven@gmail.com

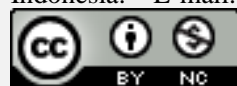

This work is licensed under a Creative Commons Attribution-NonCommercial 4.0 International License.

How to cite this article in accordance with the American Psychological Association (APA) $7^{\text {th }}$ guidelines:

Lusi, R. A. (2021). Penyesuaian diri mahasiswa yang kuliah sambil bekerja. MEDIAPSI, 7(1), 5-16. https://doi.org/10.21776/ub.mps.2021.007.01.2

\section{Pendahuluan}

Kuliah sambil bekerja merupakan fenomena yang umum terjadi, baik di
Indonesia (Dirmantoro, 2015) maupun di luar negeri (Boatman \& Long, 2016). Peran ganda tersebut tentunya tidak mudah untuk 
dijalani, yang memberikan sejumlah tantangan tersendiri dan menentukan sejauh mana mahasiwa yang kuliah sambil bekerja mampu melakukan penyesuaian diri secara positif atau efektif dalam menempuh dan menyelesaikan kuliah mereka. Tantangan tersebut bisa berupa waktu yang lebih sedikit untuk belajar (Mardelina \& Muhson, 2017) dan juga prokrastinasi dalam menyelesaikan tugas perkuliahan (Arumsari \& Muzaqi, 2016). Mengetahui bagaimana mahasiswa yang kuliah sambil bekerja melakukan penyesuaian diri merupakan hal yang penting karena penyesuaian diri telah ditemukan berkontribusi signifikan terhadap prestasi belajar mahasiswa (Arifin dkk., 2016; da Costa dkk., 2018; Suryadi dkk., 2020; van Rooij dkk., 2018).

Terlepas bahwa fenomena kuliah sambil bekerja jamak terjadi, masih jarang penelitian yang dilakukan untuk mengetahui bagaimana mahasiswa yang kuliah sambil bekerja melakukan penyesuaian diri dalam menghadapi peran ganda tersebut. Penelitian sebelumnya di Indonesia yang mengangkat tema tentang mahasiswa yang kuliah sambil bekerja memang cukup memadai jumlahnya (contoh: Ario \& Anganthi, 2020; Oktaviani \& Adha, 2020; Suwarso, 2018). Meskipun demikian, masih relatif jarang penelitian sebelumnya yang berfokus pada tema penyesuaian diri pada mahasiswa yang kuliah sambil bekerja. Mengacu pada kesenjangan tersebut, pengungkapan bentukbentuk penyesuaian diri mahasiswa yang kuliah sambil bekerja merupakan tujuan penelitian ini.

Banyak remaja, setelah lulus pendidikan sekolah menengah atas, selanjutnya meneruskan pendidikan ke perguruan tinggi. Hal ini dilakukan dengan berbagai alasan, mulai dari aspirasi untuk bisa menempuh dan mendapatkan gelar pendidikan tinggi, memperdalam ilmu pengetahuan, sampai dengan mengembangkan diri (Remenick \& Bergman, 2020). Setelah menempuh dan memperoleh gelar sarjana, beberapa mahasiswa kemudian berminat dan memutuskan untuk melanjutkan studi ke jenjang magister. Dalam pelaksanaannya dapat kita jumpai mahasiswa yang full time study, dan juga mahasiswa yang melanjutkan studi sambil bekerja dikarenakan berbagai alasan seperti faktor kurang kondusifnya ekonomi keluarga atau dorongan untuk menambah pengalaman dan jaringan kerja (Ario \& Anganthi, 2020).

Mahasiswa yang menjalankan aktivitas perkuliahan sambil bekerja harus diakui bisa memperoleh sejumlah keuntungan, terutama berupa bertambahnya penghasilan, pengalaman bekerja, dan kemandirian. Dampak negatifnya, mereka juga mengalami permasalahan dalam kehidupannya. Mahasiswa yang juga pekerja harus menjalani peran lebih berat dibandingkan mahasiswa yang tidak bekerja. Sambil menjalankan perkuliahan mereka di kampus, mahasiswa tersebut juga dibebani dengan tanggung jawab untuk mampu menyelesaikan tugas-tugas di tempat kerja mereka (Felix dkk., 2019). Dalam kehidupan di kampus atau perkuliahan, mahasiswa harus mengemban berbagai macam tugas yang rumit, mulai dari memahami dan menguasai literatur ilmiah sampai dengan berkonsultasi dengan dosen untuk menanyakan topik-topik dan tugas-tugas perkuliahan (Arjanggi \& Kusumaningsih, 2016). Berbagai masalah juga sering dihadapi oleh mahasiswa yang bekerja di tempat kerjanya termasuk kerja yang ajeg, perselisihan relasional dengan sesama rekan kerja dan dengan atasan, kompetisi, gaji yang kurang mencukupi, dan akumulasi 
beban kerja (Owen dkk., 2018). Penelitian Felix dkk. (2019) mengungkapkan pada sejumlah mahasiswa STMIK Mikroskil Medan bahwa kuliah sambil bekerja memunculkan sejumlah kesulitan dalam pengaturan waktu, penyelesaian tugas kerja dan kuliah secara bersamaan, serta dalam mengatur konsentrasi atau fokus pada kerja dan kuliah. Kesulitan lain yang juga dihadapi adalah kelelahan fisik sebagai akibat dari kecilnya jeda waktu antara kuliah dan bekerja. Dampak negatif yang mereka alami adalah kesulitan mengerjakan dan menyelesaikan tugas kuliah karena mereka juga harus mendedikasikan waktu untuk menunaikan pekerjaannya di tempat kerja.

Tuntutan-tuntutan maupun permasalahan-permasalahan yang ada dalam perkuliahan dan pekerjaan mengharuskan mahasiswa yang kuliah sambil bekerja untuk secara bersamaan memenuhinya. Tugas ini menuntut mereka mampu berupaya ekstra agar dapat menjalani dan memenuhi tuntutan-tuntutan yang ada baik sebagai mahasiswa dan juga sebagai pekerja (Darolia, 2014; Gaedke dkk., 2012).

Salah satu bentuk upaya yang dapat dilakukan yaitu dengan melakukan penyesuaian diri. Haber dan Runyon (1984) serta Harahap (2021) menyatakan bahwa sebagai proses yang dinamis, penyesuaian diri mencerminkan kemampuan individu untuk mengubah perilaku, dengan tujuan agar individu bisa lebih harmonis dengan lingkungan sosialnya dan lebih mampu menghadapi tekanan hidup baik secara internal maupun eksternal. Chaplin (2002) dan juga Maddux (2013) mengemukakan bahwa penyesuaian diri mencerminkan adanya variasi kegiatan yang dilakukan individu agar individu mampu beradaptasi dengan situasi dan kondisi eksternal, baik yang bersifat sosial maupun fisik.
Kemampuan beradaptasi tersebut selanjutnya memfasilitasi individu memenuhi kebutuhan-kebutuhan psikologis mereka.

Setiap individu pasti menemui cobaan dan kesulitan, bahkan frustasi dalam memuaskan kebutuhan-kebutuhan psikologis mereka. Penyesuaian diri merupakan respon individu dalam beradaptasi dan selanjutnya mampu mengatasi handikap-handikap kehidupan, baik yang berasal dari diri individu itu sendiri maupun dari luar diri individu, yang meningkatkan kemampuan individu untuk menyelaraskan diri mereka dengan lingkungan sekitar di mana mereka hidup (Delle Fave, 2014; Schneiders, 1999).

Umumnya, penyesuaian diri merefleksikan kewajaran cara bereaksi dan bertingkah laku individu. Semenjak berusia dini, individu telah berupaya melakukan penyesuain diri dengan mengembangkan sikap dan perilaku tertentu sesuai dengan tahap perkembangan yang mereka jalani (Widyanoor \& Pranoto, 2019; Sobur, 2003). Penyesuaian diri yang baik terwujud apabila individu mampu menyelaraskan kebutuhannya dengan tuntutan-tuntutan di lingkungan sekitarnya. Sejumlah ciri-khas menandai penyesuaian diri yang baik atau optimal. Karakteristik-karakteristik tersebut berujud emosi dan kognisi tertentu, yang menurut Schneiders (1999) terdiri dari:

1. Ketiadaan emosi yang berlebihan, yang mencerminkan adanya kontrol emosi dari individu ketika menghadapi masalah serta merespon masalah yang ada dengan tenang sehingga mampu mengatasinya.

2. Ketiadaan mekanisme psikologis dimana individu tidak melakukan selfdefence mechanism yang mendorong indvidu menyalahkan orang lain, seperti 
kompensasi, $\quad$ proyeksi, serta rasionalisasi.

3. Ketiadaan perasaan frustrasi pribadi, yang tercermin dengan reaksi secara normal terhadap permasalahan yang dialami dan juga tingkah laku yang efisien dalam mengatasi suatu permasalahan.

4. Rasional dalam mempertimbangkan dan mengarahkan diri sendiri (self direction) sebagai kemampuan untuk melihat atau menghadapi permasalahan yang ada dengan pikiran yang sehat dan masuk akal.

5. Kemampuan untuk belajar, yang terukur atas dasar usaha positif yang secara terus-menerus dilakukan oleh individu untuk mengatasi permasalahan yang ada.

6. Kemampuan menggunakan pengalaman masa lalu sebagai kemampuan individu untuk mengatasi masalah dengan mengingat kembali hal-hal baik dan menguntungkan ketika menghadapi masalah.

7. Sikap realistik dan objektif sebagai kemampuan individu untuk menerima kenyataan yang ada tanpa menciptakan konflik baru serta objektif dalam melihat permasalahan yang ada.

Dengan melakukan penyesuaian diri, individu yang menjalani peran ganda sebagai mahasiswa dan juga sebagai pekerja diharapkan dapat mencapai keselarasan dan kehamonisan dengan diri sendiri dan lingkungannya (Schneiders, 1999). Selain itu, sebagaimana dikemukakan oleh Sitorus dan Warisot WS (2013), dengan melakukan penyesuaian diri individu yang menjalani peran ganda ini (mahasiswa yang sekaligus sebagai pekerja) akan mampu mengatasi stres dan kecaman, mempunyai self image yang positif, mampu untuk mengungkapkan perasaan, serta memiliki hubungan interpersonal yang baik.

Penelitian ini bertujuan untuk mengungkapkan atau membahasakan kembali bagaimana atau sejauh mana penyesuaian diri yang dilakukan oleh informan dalam manjalani kehidupannya sebagai seorang mahasiswa dan juga seorang pekerja. Hasil yang diproyeksikan dari penulisan ini adalah diperolehnya gambaran dinamika penyesuaian diri yang dilakukan oleh mahasiswa yang kuliah sambil bekerja dalam menjalani peran gandanya tersebut.

\section{Metode}

\section{Partisipan dan desain penelitian}

Dalam penelitian ini informan penelitian adalah seorang mahasiswa yang sekaligus berperan sebagai pekerja. Pemilihan informan dilakukan secara purposive. Dengan metode ini, peneliti memilih informan berdasarkan kriteria tertentu yang sudah ditetapkan oleh peneliti sebelumnya. Informan adalah seorang pekerja kantoran yang kemudian memutuskan untuk melanjutkan studi mengambil program magister di salah satu universitas swasta di Kota Surabaya. Pemilihan jurusan oleh informan berbeda dari jurusan yang diambil sebelumnya. Hal ini membuat informan membutuhkan penyesuaian diri untuk menjalani kehidupan perkuliahan dan juga kehidupan kerja.

Penelitian ini menggunakan pendekatan kualitatif yang memposisikan informan yang diteliti sebagai entitas dan fenomena natural dan peneliti sebagai instrumen kunci penelitian. Menggunakan teknik triangulasi, peneliti menganalisa data secara induktif. Dengan model analisa induktif ini, peneliti menafsirkan hasil penelitian atas dasar makna dan bukannya 
generalisasi (Sugiyono, 2018), serta atas dasar perspektif fenomenologis dengan menekankan pengalaman subjektif dan pemaknaan relatif terhadap pengalaman tersebut oleh masing-masing individu (Camic dkk., 2003).

\section{Prosedur dan pengukuran}

Peneliti melalui proses interview melakukan interaksi dengan informan. Dalam interview ini, peneliti melakukan tanya-jawab dengan informan, yang selanjutnya hasil tanya-jawab tersebut dikompilasi sebagai data penelitian. Data tersebut peneliti konstruksikan sebagai makna untuk mengidentifikasi topik atau tema tertentu (Sugiyono, 2018). Wawancara dilakukan berdasarkan guided interview yang telah disiapkan oleh peneliti sebelumnya. Pertanyaan-pertanyaan dalam proses wawanacara disusun oleh peneliti berdasarkan teori penyesuaian diri yang dikemukakan oleh Schneiders (1999), yaitu penyesuaian diri secara emosional dan penyesuaian diri secara kognitif dengan aspek-aspek di setiap jenis penyesuaian diri.

Analisis data dalam penelitian ini menggunakan teknik koding wawancara. Koding merupakan teknik mengidentifikasi kata-kata atau frase. Dalam koding, katakata atau frase tersebut diasumsikan mempengaruhi munculnya fakta psikologis yang kuat, dan membantu peneliti untuk mengungkap inti fakta, serta menentukan aspek-aspek psikologis yang muncul secara kuat dengan mengacu pada data visual dan kumpulan bahasa (Saldana, 2009). Peneliti melakukan koding dengan cara mengelompokkan respon informan dalam kategori atau tema yang sudah ditentukan oleh peneliti, yaitu penyesuaian diri dengan aspek-aspeknya.

\section{Hasil}

Tabel 1 pada halaman berikut menampilkan hasil wawancara dengan informan penelitian. Hasil wawancara disusun atas dasar tema besar, tema kecil, coding, dan teori pendukung.

Hasil wawancara, sebagaimana bisa dicermati pada Tabel 1, menunjukkan bahwa informan telah atau sudah melakukan penyesuaian diri dalam menjalani kehidupannya baik sebagai seorang pekerja kantor maupun sebagai seorang mahasiswa. Bentuk penyesuaian diri yang dilakukan oleh informan mencakup penyesuaian diri secara emosional dan juga penyesuaian diri secara kognitif.

Secara emosional, informan tidak menunjukkan reaksi emosi yang berlebihan ketika menghadapi tuntutan-tuntutan dalam kehidupannya baik tuntutan dalam studi maupun tuntutan dalam pekerjaan. Ketika menghadapi suatu tuntutan, informan berupaya menerimanya dan berusaha untuk menemukan solusi atau cara pemenuhannya. Sementara itu, ketika mengalami kegagalan atau ketidakmampuan dalam menghadapi tuntutan, informan menunjukkan kecenderungan defensif dengan menyalahkan orang lain dan mengekspresikan emosi marah terhadap orang lain. Meskipun demikian, mekanisme defensif tersebut hanya bersifat sementara. Secara keseluruhan, dalam melaksanakan dan memenuhi tuntutan yang ada, informan mampu berkompromi dengan diri sendiri. Ketika gagal dalam berupaya memenuhi suatu tuntutan, informan berusaha menurunkan standar atau patokan dalam pemenuhan tuntutannya sehingga menjadi lebih terbisa menghadapi kegagalan.

Penyesuaian diri secara kognitif dapat dilihat dari beberapa upaya yang dilakukan oleh informan. Pertama, informan 
mampu melakukan penyesuaian diri ketika menghadapi masalah, konflik, atau tuntutantuntutan yang ada. Informan sering menggunakan waktu ketika bekerja untuk menyelesaikan tugas-tugas perkuliahan. Hal ini tentunya dilakukan setelah tugas-tugas atau pekerjaan kantornya telah selesai dikerjakan atau pada saat tidak ada pekerjaan kantor yang harus diselesaikan. Ketika menghadapi tantangan dalam pemenuhan tuntutan, khususnya tuntutan dalam perkuliahan yang kebetulan tidak linear dengan disiplin ilmu sarjananya, informan berupaya untuk memenuhi tuntutan yang ada dengan bertanya kepada teman kuliah, pergi ke perpustakaan untuk mencari literatur, dan juga memanfaatkan fasilitas internet untuk belajar materi perkuliahan.

Tabel 1. Coding Transkrip Hasil Wawancara.

\begin{tabular}{|c|c|c|c|}
\hline Tema besar & Tema kecil & Coding & Teori pendukung \\
\hline Penyesuaian diri emosional & $\begin{array}{c}\text { Ketiadaan emosi yang } \\
\text { berlebihan }\end{array}$ & $\begin{array}{l}\text {..."Sampai sejauh ini tugas-tugasnya } \\
\text { masih bisa ditoleran sih. Masih bisa } \\
\text { saya selesaikan..." (W1P1B86) } \\
\text {..."saya belajar untuk lebih aaa } \\
\text { memaafkan diri yaa, hahaha } \\
\text { (tertawa). Karena yaa pastilah ada } \\
\text { kerjaan itu yang keluar deadline } \\
\text { gitu ada, yang harusnya SOP } \\
\text { dikerjain itu laporan satu minggu } \\
\text { setelah observasi harus sudah } \\
\text { selesai, tapi ada yang saya tidak } \\
\text { bisa selesaikan karena saya punya } \\
\text { alasan gitu kan..." (W1P1B97-99) } \\
\text {...'Jadi buat saya kegagalan di } \\
\text { tempat kerja itu aaa cara saya } \\
\text { menyikapinya yaa berusaha untuk } \\
\text { apa yaa, gak terlalu perfeksionis } \\
\text { gitu..." (W1P1B102-103) } \\
\text {..Jadi aaa kalau saya ada masalah } \\
\text { biasanya saya langsung kelihatan } \\
\text { gitu. Aaaa saya diam aja atau nggak } \\
\text { gitu malah saya itu cenderung } \\
\text { ngomel-ngomel tergantung tingkat } \\
\text { masalahnya gitu...." (W1P1B35-37) } \\
\text {..."Dalam artian saya lebih } \\
\text { menekan orang lain kemudian saya } \\
\text { dengan kata-kata saya yang } \\
\text { mungkin saya akan aaa, tidak } \\
\text { mungkin yaaa karena saya nih } \\
\text { ekstrovert jadi saya cerita, tapi } \\
\text { dengan cerita itu sebenarnya saya } \\
\text { sedang memojokkan orang gitu. } \\
\text { Menekan orang lain dengan kata- } \\
\text { kata saya.." (W1PIB44-47) }\end{array}$ & $\begin{array}{c}\text { Mekanisme pertahanan } \\
\text { diri }\end{array}$ \\
\hline
\end{tabular}


Tabel 1. (lanjutan).

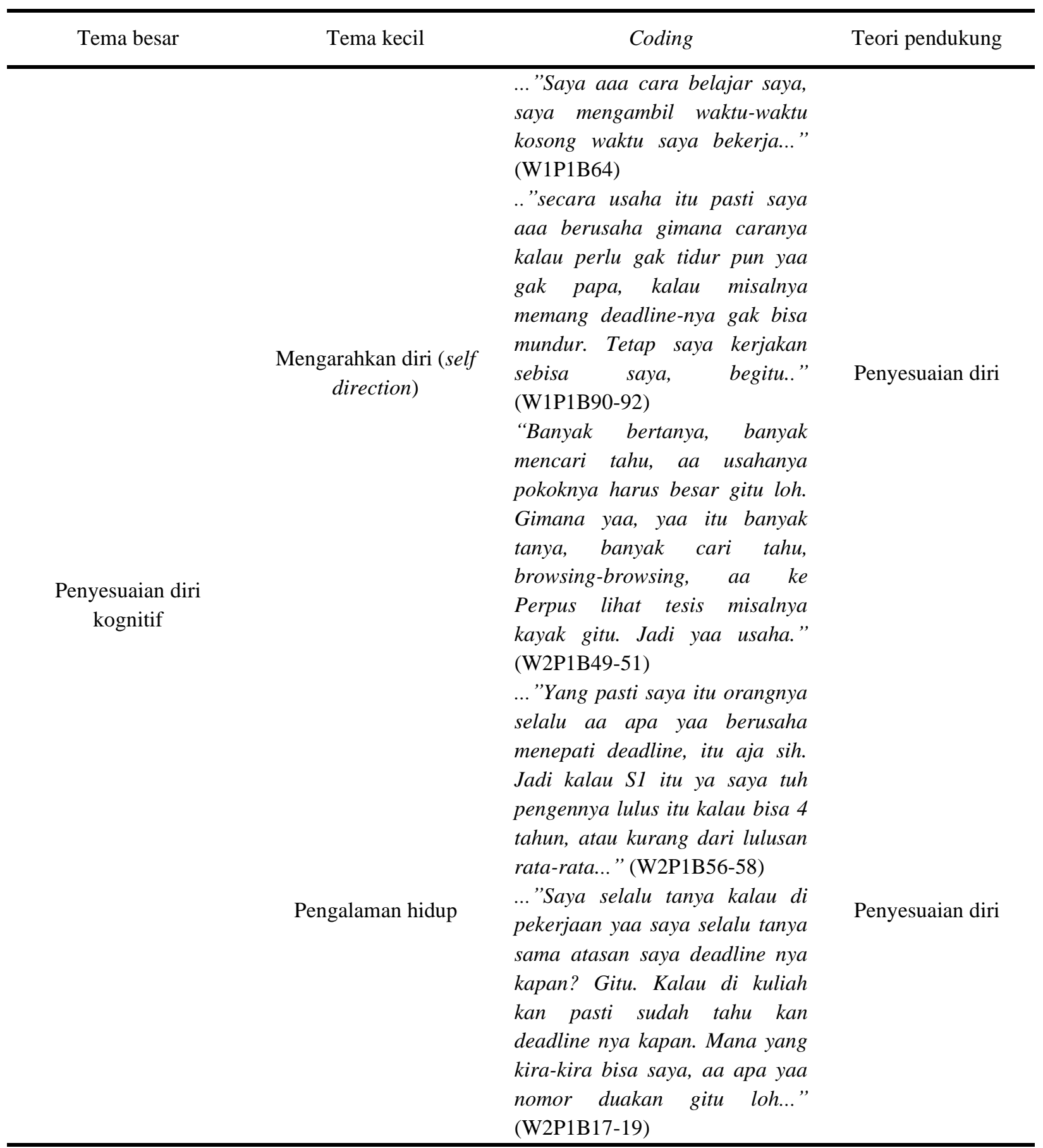

Keterangan. $\mathrm{W}=$ wawancara; $\mathrm{P}=$ partisipan/informan; $\mathrm{B}=$ baris.

\section{Diskusi}

Penelitian ini menggunakan pendekatan kualitatif yang bertujuan untuk mengungkap dan menjelaskan bentukbentuk penyesuaian diri mahasiswa yang kuliah sekaligus bekerja. Hasil penelitian menunjukkan bahwa informan mampu melakukan penyesuaian diri secara emosional maupun kognitif dalam menjalankan peran ganda sebagai seorang mahasiswa di program magister dan sebagai seorang karyawan. 
Hasil penelitian di atas menunjukkan kemampuan informan dalam melakukan penyesuaian diri secara positif (Mahmudi \& Suroso, 2014). Individu dengan penyesuaian diri positif mampu secara efektif meregulasi emosinya dan tidak mudah mengalami frustasi dalam meraih harapan atau keinginan (Park dkk., 2012). Mereka juga mampu melakukan pertimbangan dan pengarahan diri yang rasional, memetik pelajaran dari pengalaman yang dimiliki, serta realitis dan objektif dalam menyikapi tantangan-tantangan kehidupan (Delle Fave, 2014; Schneiders, 1999). Meskipun demikian, terdapat penyesuaian diri yang salah (negatif) yang juga dilakukan oleh informan dalam menjalani peran gandanya sebagai mahasiswa dan pekerja. Penyesuaian diri ini dilakukan dengan membentuk mekanisme pertahanan diri ketika menghadapi tuntutan khususnya dalam tuntutan pekerjaan. Dalam kasus ini, mekanisme mekanisme pertahanan diri yang dilakukan oleh subjek sesuai dengan yang dikemukanan Hasneli dan Ulfa (2017), yaitu rasionalisasi dan proyeksi. Bentuk mekanisme ini dilakukan informan sebagai mekanisme defensif untuk menyangkal kegagalan dan sebagai upaya menunjukkan bahwa dirinya tidak mengalami kesulitan dengan cara mencari-cari alasan (rasionalisasi) serta melemparkan kesalahan yang dilakukan kepada pihak lainnya (proyeksi).

Mekanisme defensif di atas, yaitu rasionalisasi dan proyeksi, dilakukan oleh informan secara tentatif, dan bukannya menetap atau persisten. Informan secara umum tidak mempersalahkan tuntutantuntutan yang diterimanya. Informan merupakan individu yang sangat berorientasi pada tugasnya sehingga melakukan upaya yang maksimal agar tuntutan-tuntutannya dapat terpenuhi. Sebagaimana dikemukakan oleh beberapa peneliti (He \& Côté, 2019;
Rahat \& İlhan, 2016), individu yang mampu melakukan penyesuaian diri menjadikan tuntutan-tuntutan tersebut sebagai tantangan, dan bukannya rintangan yang harus ditemukan solusinya. Dengan melakukan penyesuaian diri yang baik, indvidu dengan demikian mampu berjuang, dan menjadi lebih tangguh serta kompeten dalam menghadapi tuntutan-tuntutan tersebut. Meskipun demikian, ada standar yang sudah dimiliki oleh informan ketika berupaya untuk memenuhi tuntutan yang ada. Menghadapi standar tersebut, informan harus memahami detail dari setiap tuntutan yang diberikan dan selanjutnya memutuskan cara atau upaya yang dilakukan untuk memenuhi atau menyelesaikan tuntutan yang ada dalam kehidupannya.

Penelitian ini mengandung kebaruan dengan mengangkat tema tentang penyesuaian diri pada mahasiswa yang menjalankan peran ganda sebagai mahasiswa dan pekerja, yang relatif jarang diselidiki. Meskipun demikian, beberapa kekurangan dalam penelitian ini layak dielaborasi. Kekurangan pertama berkaitan dengan penggunaan satu informan. Untuk menutupi kekurangan ini, riset atau studi lanjutan yang berminat menyelidiki tema yang sama diharapkan bisa merekrut informan yang lebih mencukupi, dengan tujuan untuk mendapatkan bentuk-bentuk dan aspekaspek penyesuaian diri yang lebih bervariasi, yang dilakukan oleh mahasiswa yang kuliah sambil bekerja. Studi lanjutan juga bisa membandingkan mahasiswa yang kuliah sambil bekerja atau part-time student dan mahasiswa yang kuliah tanpa bekerja atau full-time student (contoh: Darolia, 2014; MacCann dkk., 2012), untuk menganalisis perbedaan penyesuaian diri antara kedua kelompok mahasiswa tersebut. Kelemahan kedua berkaitan dengan pendekatan kualitatif. Untuk mengatasi kelemahan ini, studi atau riset lanjutan bisa menerapkan 
desain kuantitatif, dengan tujuan mengidentifikasi faktor-faktor yang mempengaruhi atau memprediksi (contoh: DeAndrea dkk., 2012; Katz \& Somers, 2017; Nordstrom dkk., 2014) serta dampakdampak (contoh: Credé \& Niehorster, 2012; Kaljahi, 2016) dari penyesuaian diri, yang selanjutnya dikontekstualisasikan di kalangan mahasiswa yang kuliah sambil bekerja.

\section{Kesimpulan}

Mahasiswa yang menempuh kuliah tetapi secara bersamaan mencari nafkah harus mampu melakukan penyesuaian diri baik secara emosional maupun kognitif. Penyesuaian diri tersebut menentukan sejauh mana mahasiswa yang kuliah sambil bekerja mampu memecahkan berbagai macam rintangan secara efektif, baik rintangan yang berkaitan dengan tugas-tugas kuliah maupun pekerjaan. Pernyataan-pernyataan tersebut menjadi intisari hasil penelitian ini, yang berimplikasi pada pentingnya bagi mahasiswa yang kuliah sambil bekerja untuk mampu mengidentifikasi dan menerapkan faktor-faktor yang meningkatkan penyesuaian diri dalam menjalankan peran ganda mereka.

\section{Daftar Pustaka}

Arifin, M., Dardiri, A., \& Handayani, A. N. (2016). Hubungan kemampuan penyesuaian diri dan pola berpikir dengan kemandirian belajar serta dampaknya pada prestasi akademik mahasiswa. Jurnal Pendidikan: Teori, Penelitian, dan Pengembangan, 1(10), 1943-1951.

http://doi.org/10.17977/jp.v1i10.7105

Ario, T. S., \& Anganthi, N. R. N. (2020). Problematika pada mahasiswa pekerja paruh waktu(Disertasi, Universitas Muhammadiyah Surakarta).
http://eprints.ums.ac.id/82213/10/NAS KAH\%20PUBLIKASI.pdf

Arjanggi, R., \& Kusumaningsih, L. P. S. (2016). The correlation between social anxiety and academic adjustment among freshmen. Procedia-Social and Behavioral Sciences, 219, 104-107. https://doi.org/10.1016/j.sbspro.2016.0 4.049

Arumsari, A. D., \& Muzaqi, S. (2016). Prokrastinasi akademik pada mahasiswa yang bekerja. E-Jurnal Spirit Pro Patria,2(2), 30-39. https://doi.org/10.29138/spirit\%20pro $\% 20$ patria.v2i2.534

Boatman, A., \& Long, B. T. (2016). Does financial aid impact college student engagement?. Research in Higher Education, 57(6), 653-681. https://doi.org/10.1007/s11162-0159402-y

Camic, P. M., Rhodes, J. E., \& Yardley, L. E. (2003). Qualitative research in psychology: Expanding perspectives in methodology and design. American Psychological Association.

Chaplin, J. P. (2002). Kamus lengkap psikologi. Rajawali Press.

Credé, M., \& Niehorster, S. (2012). Adjustment to college as measured by the student adaptation to college questionnaire: A quantitative review of its structure and relationships with correlates and consequences. Educational Psychology Review, 24(1), 133-165. https://doi.org/10.1007/s10648-0119184-5

da Costa, A., Hanurawan, F., Atmoko, A., \& Hitipeuw, I. (2018). The impact of self-adjustment on academic achievement of the students. ISLLAC: Journal of Intensive Studies on Language, Literature, Art, and 
Culture, 2(1),

1-6. http://doi.org/10.17977/um006v2i1201 8p001

Darolia, R. (2014). Working (and studying) day and night: Heterogeneous effects of working on the academic performance of full-time and part-time students. Economics of Education Review, 38, 38-50 https://doi.org/10.1016/j.econedurev.2 013.10 .004

DeAndrea, D. C., Ellison, N. B., LaRose, R., Steinfield, C., \& Fiore, A. (2012). Serious social media: On the use of social media for improving students' adjustment to college. The Internet and Higher Education, 15(1), 15-23. https://doi.org/10.1016/j.iheduc.2011.0 5.009

Delle Fave, A. (2014). Harmony. In A. C. Michalos (Ed.), Encyclopedia of quality of life and well-being research. Springer. https://doi.org/10.1007/978-94-0070753-5_1231

Dirmantoro, M. (2015). Motivasi mahasiswa kuliah sambil bekerja (Disertasi, Universitas Islam Negeri Maulana Malik Ibrahim). http://etheses.uinmalang.ac.id/3120/1/11410083.pdf

Felix, T., Marpaung, W., \& El Akmal, M. (2019). Peranan kecerdasan emosional pada pemilihan strategi coping pada mahasiswa yang bekerja. Persona: Jurnal Psikologi Indonesia, 8 (1), 3956.

https://doi.org/10.30996/persona.v8i1. 2377

Gaedke, G., Venegas, B. C., Simbrunner, P., \& Janous, G. (2012). Impact of stress factors on part-time college students. International Journal for Cross-Disciplinary Subjects in Education, 3(2), 692-698. https://doi.org/10.20533/ijcdse.2042.63 64.2012.0098

Haber, A., \& Runyon, R. P. (1984). Psychology of adjustment. The Dorsey Press.

Harahap, F. A. Z. (2021). Self adjustment dynamic in sojourner college students. Journal of Psychology and Instruction, 4(3), 83-89. http://doi.org/10.23887/jpai.v4i3.3370 3

Hasneli \& Ulfa, F. F. (2017). Hubungan kecerdasan emosional dengan penyesuaian diri pada siswa MTsN. AlQalb, Jurnal Psikolgi Islam, 9(1), 817.

https://core.ac.uk/download/pdf/28810 0428.pdf

He, J. C., \& Côté, S. (2019). Self-insight into emotional and cognitive abilities is not related to higher adjustment. Nature Human Behaviour, 3(8), 867-884. https://doi.org/10.1038/s41562-0190644-0

Kaljahi, N. E. (2016). The Effects of academic adjustment, social adjustment and personal-emotional adjustment of students on their academic performance in Universities of Northern Cyprus (Master's thesis, Eastern Mediterranean University (EMU)-Doğu Akdeniz Üniversitesi (DAÜ)). http://irep.emu.edu.tr:8080/jspui/bitstream/11 129/2927/1/kaljahiniusha.pdf

Katz, S., \& Somers, C. L. (2017). Individual and environmental predictors of college adjustment: Prevention and intervention. Current

Psychology, 36(1), $56-65$. http://doi.org/10.1007/s12144-0159384-0

MacCann, C., Fogarty, G. J., \& Roberts, R. D. (2012). Strategies for success in education: Time management is more 
important for part-time than full-time community college students. Learning and Individual Differences, 22(5), 618623.

https://doi.org/10.1016/j.lindif.2011.09 .015

Maddux, J. E. (Ed.). (2013). Self-efficacy, adaptation, and adjustment: Theory, research, and application. Springer Science \& Business Media.

Mahmudi, M. H., \& Suroso. (2014). Efikasi diri, dukungan sosial, dan penyesuaian diri dalam belajar. Persona: Jurnal Psikologi Indonesia, 3(2), 183-194. https://doi.org/10.30996/persona.v3i02 .382

Mardelina, E., \& Muhson, A. (2017). Mahasiswa bekerja dan dampaknya pada aktivitas belajar dan prestasi akademik. Jurnal Economia, 13(2), 201-209.

http://staffnew.uny.ac.id/upload/13223 2818/penelitian/Elma\%20Mardelina\% 20dan\%20Ali\%20Muhson\%20(2017) \%20Mahasiswa\%20Bekerja.pdf

Nordstrom, A. H., Goguen, L. M. S., \& Hiester, M. (2014). The effect of social anxiety and self-esteem on college adjustment, academics, and retention. Journal of College Counseling, 17(1), 48-63. https://doi.org/10.1002/j.21611882.2014.00047.x

Oktaviani, S., \& Adha, A. S. (2020). Analisis motivasi kuliah sambil bekerja pada mahasiswa PGSD FKIP Universitas Widya Gama Mahakam Samarinda. Media Penelitian Pendidikan: Jurnal Penelitian dalam Bidang Pendidikan dan Pengajaran, 14(2), 153-157. https://doi.org/10.26877/mpp.v14i2.59 65

Owen, M. S., Kavanagh, P. S., \& Dollard, M. F. (2018). An integrated model of MEDIAPSI | 2021, Vol. 7, No. 1, 5-16 work-study conflict and work-study facilitation. Journal of Career Development, 45 (5), 504-517. https://doi.org/10.1177\%2F089484531 7720071

Park, C. L., Edmondson, D., \& Lee, J. (2012). Development of self-regulation abilities as predictors of psychological adjustment across the first year of college. Journal of Adult Development, 19(1), 40-49. https://doi.org/10.1007/s10804-0119133-z

Rahat, E., \& İlhan, T. (2016). Coping styles, social support, relational selfconstrual, and resilience in predicting students' adjustment to university life. Educational Sciences: Theory and Practice, 16(1), 187-208. https://doi.org/10.12738/estp.2016.1.0 058

Remenick, L., \& Bergman, M. (2020). Support for working students: Considerations for higher education institutions. The Journal of Continuing Higher Education, 69(2), 1-12. https://doi.org/10.1080/07377363.2020 .1777381

Saldana, J. (2009). The coding manual for qualitative researcher. Sage.

Schneiders, A. A., (1999). Personal adjustment and mental health. Holt, Reinhart and Winston Inc.

Sitorus, L. I. S., \& Warsito WS, H. (2013). Perbedaan tingkat kemandirian dan penyesuaian diri mahasiswa perantauan suku Batak ditinjau dari jenis kelamin. Character, 1(2), 1-6. https://jurnalmahasiswa.unesa.ac.id/ind ex.php/character/article/view/1917/532 4

Sobur, A. (2003). Psikologi umum. Pustaka Setia. 
Sugiyono. (2018). Metode penelitian pendidikan: Pendekatan kuantitatif, kualitatif, dan $R \& D$. Alfabeta.

Suryadi, S., Triyono, T., Nur, A., \& Dianto, M. (2020). Hubungan penyesuaian diri dan motivasi belajar dengan prestasi belajar siswa. Jurnal Neo Konseling, 2(1). 1-9. http://doi.org/10.24036/00245kons202 0

Suwarso, S. (2018). Dampak kuliah sambil bekerja terhadap indeks prestasi mahasiswa perguruan tinggi negeri dan swasta di Kabupaten Jember tahun 2017. RELASI: JURNAL EKONOMI, 14(2), 15-27. https://doi.org/10.31967/relasi.v14i2.2 61

van Rooij, E. C., Jansen, E. P., \& van de Grift, W. J. (2018). First-year university students' academic success: The importance of academic adjustment. European Journal of Psychology of Education, 33(4), 749767. https://doi.org/10.1007/s10212017-0347-8

Widyanoor, C. J., \& Pranoto, Y. K. S. (2019). The influence of selfadjustment on social interaction of 4-5 years children. BELIA: Early Childhood Education Papers, 8(1), 2127.

https://doi.org/10.15294/belia.v8i1.297 86 